\title{
Radioxenon Spiked Air
}

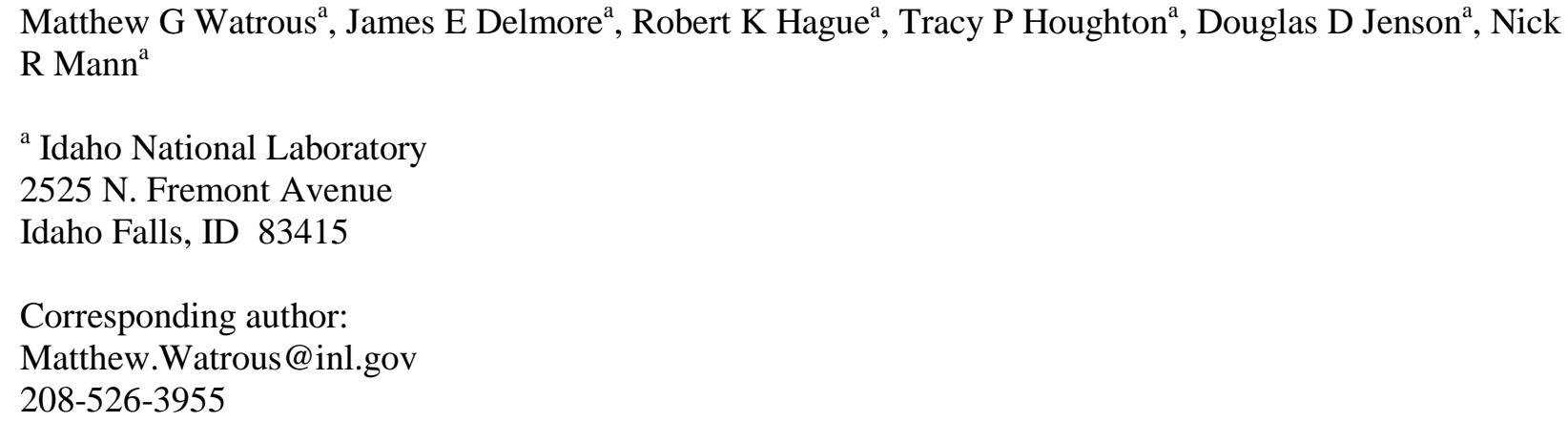




\section{Abstract}

Four of the radioactive xenon isotopes $\left({ }^{131 \mathrm{~m}} \mathrm{Xe},{ }^{133 \mathrm{~m}} \mathrm{Xe},{ }^{133} \mathrm{Xe}\right.$ and $\left.{ }^{135} \mathrm{Xe}\right)$ with half-lives ranging from 9 hours to 12 days are produced from nuclear fission and can be detected from days to weeks following their production and release. Being inert gases, they are readily transported through the atmosphere. Sources for release of radioactive xenon isotopes include operating nuclear reactors via leaks in fuel rods, medical isotope production facilities, and nuclear weapons' detonations. They are not normally released from fuel reprocessing due to the short half-lives. The Comprehensive Nuclear-Test-Ban Treaty has led to creation of the International Monitoring System. The International Monitoring System, when fully implemented, will consist of one component with 40 stations monitoring radioactive xenon around the globe. Monitoring these radioactive xenon isotopes is important to the Comprehensive Nuclear-Test-Ban Treaty in determining whether a seismically detected event is or is not a nuclear detonation. A variety of radioactive xenon quality control check standards, quantitatively spiked into various gas matrices, could be used to demonstrate that these stations are operating on the same basis in order to bolster defensibility of data across the International Monitoring System. This paper focuses on Idaho National Laboratory's capability to produce three of the xenon isotopes in pure form and the use of the four xenon isotopes in various combinations to produce radioactive xenon spiked air samples that could be subsequently distributed to participating facilities.

Keywords: Radioxenon, Xenon Spiked Air, Comprehensive Nuclear-Test-Ban Treaty (CTBT)

\section{Introduction}

A system to monitor Comprehensive Test-Ban-Treaty compliance under the Preparatory Commission is on a well-established path to maturity (Auer and Prior, 2014). This includes a planned network of 40 radioactive xenon monitoring stations with 30 stations that are established and operating (Auer and Prior, 2014; Auer et al., 2010; Ringbom et al., 2013). One component of this network is to differentiate a nuclear weapon detonation from nuclear power plant and medical isotope operations (Auer and Prior, 2014; Auer et al., 2010; Auer et al., 2004) using detection and ratio measurements of four radioactive xenon isotopes. The stations are constantly collecting samples and analyzing for radioactive xenon isotopes and isomers. These analyses consist of detection of the concentration in air and isotope/isomer ratios for each of the four isotopes and isomers: ${ }^{131 \mathrm{~m}} \mathrm{Xe},{ }^{133 \mathrm{~m}} \mathrm{Xe},{ }^{133} \mathrm{Xe}$, and ${ }^{135} \mathrm{Xe}$. When a seismic event is detected that has the possibility of being a nuclear test and the time window for xenon production overlaps with the time of the seismic event, there is a high probability that the two correlate.

In support of the world-wide non-proliferation community, Idaho National Laboratory has developed a quality assurance and quality control material production capability for radioactive xenon. The two longer-lived isotopes $\left({ }^{131 \mathrm{~m}} \mathrm{Xe}\right.$ and $\left.{ }^{133} \mathrm{Xe}\right)$ were the first to be isolated in pure form for use in standards because they are by far the easiest to procure, calibrate, and ship while still having adequate activity for accurate measurements. Addition of the other two isotopes/isomers with shorter half-lives $\left({ }^{133 \mathrm{~m}} \mathrm{Xe}\right.$ and $\left.{ }^{135} \mathrm{Xe}\right)$ has occurred more recently.

These standards include pure individual isotopes/isomers for photon energy quality control, quantitative blends of radioactive xenon isotopes/isomers for isotope ratio measurements, and production of blended radioactive xenon in an air matrix for verification of the ability to quantify radioactive xenon concentrations collected from the atmosphere.

When collecting a sample from the atmosphere, it is necessary to obtain an accurate measurement of the total air volume in order to quantify the xenon activity concentration (Auer 
et al., 2010; Auer et al., 2004). This is accomplished by cryogenically trapping both natural and fission product xenon. A huge volume of air passes through the collection system with only the xenon component and a few impurities captured. There are three systems for this function in the International Monitoring System: ARIX (Dubasov et al., 2005), SAUNA (Ringbom et al., 2003), and SPALAX (Fontaine et al., 2004). The reader is referred to these references for the separation techniques. Once sample collection is finished, this condensate is analyzed for both radioactive xenon and total xenon volume (stable and radioactive). The total volume of air is obtained by measuring the total volume of xenon combined with the concentration of xenon in air. Knowing the total volume of air and the activity level of each of the radioactive xenon isotopes, the concentration of each radioactive xenon isotope in the air sample is calculated. Because stable xenon is used to determine the quantity of air, the ideal quality control and assurance materials must be prepared in air with little, if any, additional stable xenon. When there is no alternative to the addition of non-radioactive xenon, the total quantity must be known, passed on to users, and included in calculations. The verification standards must be well blended and characterized for activity and with sufficient volume to produce a single quality control sample to be sub-sampled and made available to all participating laboratories.

\section{Radioactive Xenon Production}

Several technologies are available for production of both pure and mixed radioactive xenon isotopes that can be subsequently incorporated into radioactive xenon spiked samples.

1. Irradiation of natural xenon to obtain a mixture of all radioactive xenon isotopes in a natural xenon matrix. This material has had limited applications because the ratios of the radioactive isotopes have been less than ideal for the intended applications.

2. Irradiation of a commercially available, mass separated, stable xenon isotope to obtain a single radioactive xenon isotope in a matrix of the mass-separated stable isotope (Haas et al., 2009). This can be used to produce radioactively pure ${ }^{135} \mathrm{Xe}(9.14 \mathrm{~h})$ from massseparated ${ }^{134} \mathrm{Xe}$ (stable). This is used to calibrate the gamma spectrum in the vicinity of the 249.8-keV photon as well as for beta-gamma coincidence systems. Because it contains stable ${ }^{134} \mathrm{Xe}$ at a level that influences measurement of the total volume of air, this must be included in that calculation.

3. Isolation of mixed radioactive xenon from fission products followed by isotope separation. This is used to obtain ${ }^{133} \mathrm{Xe}(5.2475 \mathrm{~d})$ that is subsequently mass separated from accompanying ${ }^{131 \mathrm{~m}} \mathrm{Xe}$ and any other xenon isotopes. It is important to maintain very low levels of ${ }^{131 \mathrm{~m}} \mathrm{Xe}$ because the difference in half-lives will allow the ${ }^{131 \mathrm{~m}} \mathrm{Xe} /{ }^{133} \mathrm{Xe}$ ratio to increase over the course of time. ${ }^{133} \mathrm{Xe}$ can be used to calibrate the gamma spectrum in the vicinity of the $80.99-\mathrm{keV}$ photon as well as for beta-gamma coincidence systems.

4. Production of pure ${ }^{133 \mathrm{~m}} \mathrm{Xe}$ (2.198d) has been demonstrated (Perajarvi et al., 2010); however, with its short half-life, it constantly decays to the longer lived ${ }^{133} \mathrm{Xe}$ isomer. Thus, ${ }^{133 \mathrm{~m}} \mathrm{Xe}$ cannot be incorporated into a pure standard that can be shipped to another location. It is useful at the location of production, but with any shipping involved, the result is a mixture of ${ }^{133} \mathrm{Xe}$ and ${ }^{133 \mathrm{~m}} \mathrm{Xe}$. ${ }^{133 \mathrm{~m}} \mathrm{Xe}$ could be used for a quality control check of the gamma spectrum in the vicinity of the $233.2-\mathrm{keV}$ photon as well as for betagamma coincidence systems. 
5. Chemical isolation of a single radioactive isotope of an element other than xenon that subsequently decays to a pure radioactive xenon isotope. ${ }^{131} \mathrm{I}$ is commercially procured and is "milked" to obtain pure ${ }^{131 \mathrm{~m}} \mathrm{Xe}(11.84 \mathrm{~d})$ for a quality control check of the gamma spectrum in the vicinity of the $163.9-\mathrm{keV}$ photon as well as for beta-gamma coincidence systems.

6. Mixtures of all four radioactive xenon isotopes obtained by "milking" a ${ }^{252} \mathrm{Cf}$ source (McGrath et al., 2013). Application of this material is advantageous because it produces a radioactive xenon mixture with the known ${ }^{252} \mathrm{Cf}$ fission ratios. This radioactive xenon can be incorporated in any matrix and does not contain significant stable xenon to perturb the natural xenon content when used to spike air. Currently, this is the only source for ${ }^{133 \mathrm{~m}} \mathrm{Xe}$ and ${ }^{135} \mathrm{Xe}$ without additional stable xenon.

7. Quantitative blends of various combinations of ${ }^{131 \mathrm{~m}} \mathrm{Xe},{ }^{133} \mathrm{Xe}$, and ${ }^{135} \mathrm{Xe}$ in air. Blends of these isotopes are required when evaluating possible spectral interferences and for calibrating the relative sensitivities of gamma spectrometers for the respective gamma energies. Accurate measurement of isotope ratios based on these sensitivities across the Comprehensive Test-Ban-Treaty complex is critical when determining if detection of radioactive xenon (Auer and Prior, 2014) is from a nuclear detonation.

\section{Experimental}

\subsection{Pure Isotope Production}

Pure ${ }^{131 \mathrm{~m}}$ Xe: This is the easiest radioactive xenon isotope to produce, quantify, and distribute due to the longer half-life and ease of production in pure form without a stable xenon matrix. ${ }^{131 \mathrm{~m}} \mathrm{Xe}$ is the decay product of ${ }^{131} \mathrm{I} .{ }^{131} \mathrm{I}$ is the decay product of ${ }^{131} \mathrm{Te}$. ${ }^{131} \mathrm{Te}$ is produced by neutron irradiation of ${ }^{130} \mathrm{Te}$. Because ${ }^{131} \mathrm{I}(8.02 \mathrm{~d})$ is used for medical diagnostics, it is commercially available and can be "milked" to obtain ${ }^{131 \mathrm{~m}} \mathrm{Xe}$. It is received in a basic solution in a sealed bottle. The capped vial is allowed to sit for 10 to 14 days. The maximum quantity of ${ }^{131 \mathrm{~m}} \mathrm{Xe}$ contained in a sealed vial of ${ }^{131} \mathrm{I}$ is reached at 12 days post-sealing, corresponding to secular equilibrium. Greater than $90 \%$ of the maximum occurs between days 9 and 15 postsealing the vial. The bottle is placed inside a chamber (Figure 1) equipped with a helium feed and an outlet fed into a charcoal-filled tube cooled in liquid nitrogen. For collection of ${ }^{131 \mathrm{~m}} \mathrm{Xe}$, the chamber is purged with helium while the exit through the charcoal is submerged in liquid nitrogen. A typical purge time is 2 to 3 hours.

\section{Figure $1 .{ }^{131 \mathrm{~m}} \mathrm{Xe}$ collection chamber with cutaway showing plunger drops to the vial level for removal of the cap. Helium feedthroughs in top are not shown in drawing.}

To chemically purify the ${ }^{131 \mathrm{~m}} \mathrm{Xe}$ from any ${ }^{131} \mathrm{I}$ that may have reached the charcoal trap, it is passed through a gas chromatograph. The timing of the ${ }^{131 \mathrm{~m}}$ Xe elution is monitored with a sodium iodide detector connected to an audible output. When the ${ }^{131 \mathrm{~m}}$ Xe peak begins to elute, the outlet of the gas chromatograph is switched onto a liquid nitrogen-cooled charcoal trap to capture the purified ${ }^{131 \mathrm{~m}} \mathrm{Xe}$.

Pure ${ }^{133} \mathrm{Xe}$ : This is the second simplest radioactive xenon isotope to produce, quantify, and distribute due to the approximate 5-day half-life. Like ${ }^{131} \mathrm{I},{ }^{133} \mathrm{Xe}$ is a medically useful isotope 
and available commercially. It is derived from uranium fission followed by dissolution and gas extraction. In order to keep this isotope mostly free from ${ }^{131} \mathrm{Xe}$, the sample is irradiated for only a short period and chemically processed in a short period. Because the difference in half-lives of the predecessor iodine isotopes is 20.8 hours verses 8.02 days, the $133 / 131$ ratio is relatively large (how large depends on the timing of the irradiation and reprocessing). It is still necessary to conduct isotope enrichment because a highly purified sample is easier to quantify. The ${ }^{133} \mathrm{Xe}$ starting material is procured as the mixed radioactive xenon in carbon dioxide. It is processed through Idaho National Laboratory's xenon mass separator (Figure 2) to obtain high-purity ${ }^{133} \mathrm{Xe}$ (Appelhans et al., 2005).

Figure 2. Ion optic model drawing of the xenon mass separator. The wide separation between ${ }^{133} \mathrm{Xe}$ and ${ }^{131 \mathrm{~m}} \mathrm{Xe}$ is shown, along with ${ }^{134} \mathrm{Xe}$ used to monitor on a faraday cup. The ${ }^{133} \mathrm{Xe}$ is implanted in an aluminum foil.

The enrichment process is conducted using an isotope separator designed specifically for this application. The instrument is a converted VG 54 mass spectrometer with a new ion source and collector. It has a "gas tight" ion source that, during operation, has pumping from only two sources: a chemical getter pump and pumping through the very small ion beam aperture. The getter pump removes the chemically reactive gaseous impurities (mainly $\mathrm{CO}_{2}$, the diluent in the medical aliquot) while leaving xenon. The ion beam aperture is small to limit loss of xenon to the turbo pumps on the analyzer and collector sections of the instrument while allowing passage of the ion beam. The ion source has cylindrically focusing ion optics that transmit a high percentage of ions through to the collector. The overall efficiency (amount collected / amount of starting material) is $\sim 0.1 \%$. The xenon ion beams are mass separated in the magnetic sector and an electrostatic dispersion lens (Applehans et al., 2005) further increasing dispersion between the mass separated isotopes while maintaining ion beam focus. Skimmer plates remove the adjacent masses while allowing the 133 beam to reach the collector. The ion beam at mass 133 is then dispersed over a $1-\mathrm{cm}^{2}$ impact area with a scanning dispersion lens to reduce self-sputtering of previously implanted xenon. The $\mathrm{Xe}^{+}$ions are post accelerated into an aluminum foil floating at $10 \mathrm{kV}$. Post acceleration was required to implant the ions with sufficient energy so they did not diffuse back out of the foil. The foil is analyzed in a gamma well detector to determine the activity level.

Pure ${ }^{135} \mathrm{Xe}$ : This isotope is not commercially available. Production starts with commercial procurement of isotope-separated, stable ${ }^{134} \mathrm{Xe}$ which is encapsulated in a sealed, high-purity quartz ampoule for neutron irradiation. The target ${ }^{134} \mathrm{Xe}$ material is sent to the University of Texas for irradiation in the NETL reactor, then returned to INL for processing (Haas et al., 2009). The ${ }^{134} \mathrm{Xe}$ starting material is of very high purity so the resulting ${ }^{135} \mathrm{Xe}$ requires no separation from other radioactive xenon isotopes.

Mixed Fission Product from ${ }^{252} \mathrm{Cf:}{ }^{252} \mathrm{Cf}$ decays both by alpha emission and by spontaneous fission. The spontaneous fission decay mode supplies a steady source of mixed fission products, including the four radioactive xenon isotopes of interest. While the relative yields of these isotopes are well documented, the collection time alters their ratios in the collection volume, allowing some selectivity in the product ratios. These fission products are collected in a heliumfilled chamber for set periods of time. The radioactive xenon is then swept from the source and 
accumulated on a charcoal trap cooled with liquid nitrogen. One major advantage of this approach is that it provides a source, if used within a few days of collection, of all four isotopes and isomers relative to each other. A quality control test sample for the relative check of the more rare isotope $\left({ }^{133 \mathrm{~m}} \mathrm{Xe}\right.$ and $\left.{ }^{135} \mathrm{Xe}\right)$ against the somewhat more common isotopes ${ }^{131 \mathrm{~m}} \mathrm{Xe}$ and ${ }^{133} \mathrm{Xe}$ ). A previous journal article describes production details of the xenon isotopes from the californium source (McGrath et al., 2013).

Radioactive Xenon Test Materials: It is necessary to process these radioactive xenon isotopes into a form suitable for use in verification and testing that can be distributed to participating laboratories. While production (and purification when required) is different for each isotope, once the isotopes and isomers are converted to a gaseous form by the respective methods, further processing is identical. Methods have been developed for spiking one or multiple radioactive xenon isotopes or isomers into a matrix and container suitable for verification and testing that can be distributed across multiple laboratories.

The number of atoms of the radioactive xenon isotopes is so low that a carrier gas is needed for quantitative transfers. A matrix gas with similar condensation and evaporation temperatures is desirable. Stable xenon (where appropriate) and carbon dioxide are the preferred gases. Using these matrix gases, the radioactive xenon isotopes are transferred using cryogenic pumping, followed by cycling back to room temperature. In the case where stable xenon content is used to determine the quantity of processed air, carbon dioxide is the carrier of choice because it does not impact this measurement.

Production of mixed radioactive xenon from the ${ }^{252} \mathrm{Cf}$ fission source and from ${ }^{131 \mathrm{~m}} \mathrm{Xe}$ are similar because processing of both sources ends with the isotopes being absorbed on charcoal at liquid nitrogen temperature. This charcoal trap is connected to a vacuum manifold and evacuated while at liquid nitrogen temperature. This removes unwanted impurities while leaving frozen xenon behind. Once evacuated, the trap is isolated from the vacuum and allowed to warm to room temperature while monitoring the pressure. Carrier gas (carbon dioxide when spiking air) is introduced and the trap heated. After one minute of heating, the xenon or xenon/carbon dioxide mixture can be moved to a glass bulb by immersing the evacuated bulb in liquid nitrogen and then sealing the bulb with a Teflon valve. The bulb is then removed, warmed, and analyzed by gamma assay with a high-purity germanium detector.

The aluminum foil containing ${ }^{133} \mathrm{Xe}$ is placed in a quartz test tube and attached to a gas manifold. The manifold is evacuated and the foil heated to liberate ${ }^{133} \mathrm{Xe}$. After heating, the carrier gas is introduced into the tube to provide the matrix for moving ${ }^{133} \mathrm{Xe}$ into the glass bulb and isolated with a valve.

Because it is desirable to minimize the amount of stable xenon accompanying ${ }^{135} \mathrm{Xe}$, it is important to irradiate for longer times or at higher neutron fluxes (or both) to produce higher ratios of ${ }^{135} \mathrm{Xe} /$ stable xenon. This level of ${ }^{134} \mathrm{Xe}$ is included in the calculations of the materials and is essential information to pass on with the verification and testing materials. At the same time, this ${ }^{134} \mathrm{Xe}$ is adequate to function as a carrier for ${ }^{135} \mathrm{Xe}$. 
The ${ }^{135} \mathrm{Xe}$ is processed by moving the quartz ampoule (post-irradiation) into a stainless steel vacuum system that includes a removable glass bulb with Teflon valve (a valve positioned to allow the quartz ampoule to be inserted into the center for crushing) and associated connecting valves and fittings to allow connection to a vacuum system. The ampoule with ${ }^{135} \mathrm{Xe}$ is placed in the valve for breaking the ampoule. The valve is evacuated, and isolated from the vacuum pump. The ampoule is crushed by manipulating the appropriate valve, releasing the xenon into the isolated vacuum. It is then condensed in a destination glass bulb immersed in liquid nitrogen (Figure 3).

Figure 3. Manifold with destination vessel for cryogenic transfer, vacuum, and bean crushing valve. The enlargement image shows two different versions of valves used to crush beans. A ball valve and a vacuum plunger valve.

The purified radioactive isotopes (or mixture from ${ }^{252} \mathrm{Cf}$ ) in glass containers are quantitatively assayed for gamma activity in preparation for being dispensed into small, well-characterized aliquots for spiking air or other matrices. With knowledge of the activity, the quantity of gas present in the bulb is subsequently connected to a gas manifold along with one or more aliquots prepared using a calibrated sampling manifold. The aliquot(s) are isolated and characterized using; known volumes, pressure measurements, and temperature measurements. Once an aliquot is isolated from the bulk gas, it can be frozen into a small glass container for use in spiking an air sample. Once in the glass container, the amount of radioactive xenon can be assayed and represents one of the values used to determine the standard concentration.

If the verification material is an air matrix spiked with radioactive xenon, a much larger system is required than when spiking a xenon matrix. Air is purchased in gas cylinders for production of the verification material and stored for 90 days to ensure any stray radioactive xenon contained in the air at time of purchase has had time to decay away before use. Low moisture air is readily available as dry breathing air from local suppliers. Synthetic air needs to be avoided because it is generally prepared by mixing nitrogen and oxygen only. There is no guarantee for the quantity of xenon in synthetically prepared breathing air.

Compressed air is fed into the mixing tank through booster pumps and filled with more air than needed for the desired dilution. All connections to the tank are then removed and the mass of the air is measured with pressure transducers that support the tank. The tank is slowly bled down to the correct mass to dilute the spike to the correct activity concentration for the test sample. The system used is shown in Figure 4.

Figure 4. 300-L cylinder diagram showing the source air for filling, booster pumps for recycling and filling spheres, and spike breaking valves to introduce radioactive xenon to the recycle loop.

The correct mass of air and radioactive xenon spikes are brought together in the circular pumping system shown in Figure 4. The path is from the tank through the booster pumps, through two inline ball valves, and back into the mixing cylinder. Spike ampoules are placed 
introduction of air from the 300-L cylinder. The system is checked for leaks and the booster pump is started to pump the air out of the 300-L cylinder in the recycle loop through the ball valves and back into the opposite end of the mixing tank. Once flow is established, the spike is mixed with air by progressively closing the ball valve until the glass breaks to release the sample into the system, then the ball valve is returned to the fully open position. Air is pumped until 10 tank volumes have been passed through the system, at which time the test sample and air is considered mixed.

At this point, the homogenous air spiked with radioactive xenon can be moved into containers for delivery to air processing laboratories. This is done by reconfiguring the plumbing to go from the mixing cylinder through the booster pumps and into the final container. The containers are filled by monitoring pressure; however, the delivered standard quantity is a mass measurement. Regardless of how much standard is put in a container, the activity concentration for each aliquot taken from the $300-\mathrm{L}$ tank is uniform.

\section{Discussion}

Gamma assay and the mass of gas are the only two inputs to the final activity concentration. The activity is taken from the gamma assay for the xenon spike isotope and the air mass is taken from the filled tank mass. Samples may be used for comparison over time at a single laboratory, or divided and distributed to multiple laboratories for comparison studies. An example of a test sample prepared from the ${ }^{252} \mathrm{Cf}$ fission gas source is shown here:

$$
\begin{aligned}
& 17 \pm 8 \mathrm{dpm} / \mathrm{SCM}^{{ }^{131} \mathrm{~m}} \mathrm{Xe} \\
& \mathrm{T}_{0} \text { of July 15, 2013, } 1200 \mathrm{GMTu} \\
& 622 \pm 11 \mathrm{dpm} / \mathrm{SCM}^{133} \mathrm{Xe} \\
& \mathrm{T}_{0} \text { of July 15, 2013, } 1200 \text { GMT } \\
& 26.2 \pm \mathbf{5 . 4} \mathbf{~ d p m} / \mathrm{SCM}^{133 \mathrm{~m}} \mathrm{Xe} \\
& \mathrm{T}_{0} \text { of July 15, 2013, } 1200 \text { GMT } \\
& \text { 2,187 } \pm 77 \mathrm{dpm} / \mathrm{SCM}^{135} \mathrm{Xe} \\
& \mathrm{T}_{0} \text { of July 15, 2013, } 1200 \text { GMT }
\end{aligned}
$$

Concentrations were calculated from the spike beans containing $880 \pm 420 \mathrm{dpm}{ }^{131 \mathrm{~m}} \mathrm{Xe} ; 32,400$ $\pm 540 \mathrm{dpm}{ }^{133} \mathrm{Xe} ; 1,400 \pm 280 \mathrm{dpm}{ }^{133 \mathrm{~m}} \mathrm{Xe}$; and $114,000 \pm 4,000 \mathrm{dpm}{ }^{135} \mathrm{Xe}$ at $\mathrm{t}_{0}$, having been diluted in $67.4 \pm 0.3 \mathrm{~kg}$ of air. The mass of air is converted to standard cubic meters (SCM) using the definition that $1 \mathrm{SCM}$ of air has a mass of $1.2929 \mathrm{~kg}$ at $0^{\circ} \mathrm{C}, 1 \mathrm{~atm}$. An example for ${ }^{135 \mathrm{~g}} \mathrm{Xe}$ :

$$
\frac{114,000 \mathrm{dpm}}{67.4 \mathrm{~kg}} \times \frac{1.2929 \mathrm{~kg}}{\mathrm{SCM}}=2,190 \mathrm{dpm} / \mathrm{SCM}
$$

Uncertainty is propagated from the mass uncertainty for the air diluent and the assay uncertainty of the spike. The assay uncertainty is a combination of the detector calibration uncertainty and the Poisson uncertainty of the events detected. For the higher activity of the ${ }^{133} \mathrm{Xe}$ and ${ }^{135} \mathrm{Xe}$ it is dominated by the detector calibration uncertainty. As the events detected are less for the ${ }^{131 \mathrm{~m}} \mathrm{Xe}$ and the ${ }^{133 \mathrm{~m}} \mathrm{Xe}$, the Poisson uncertainty dominates.

Results show that the sample is homogenous and that the activity concentration measured on the produced test samples is consistent with the expected value from the data for the samples as 
prepared (Tables 1-4). No ${ }^{131 \mathrm{~m}} \mathrm{Xe}$ data were gathered because of the combination of low yield and a significantly lower branching ratio.

\section{Table 1. Sample 1, 5.18 SCM of air.}

Table 2. Sample 2, 4.96 SCM of air.

\section{Table 3. Sample 3, 4.93 SCM of air.}

Table 4. Sample 4, 4.89 SCM of air.

Similar results have been achieved with use of single isotopes and mixtures of isotopes and isomers.

\section{Conclusion}

Methods have been developed and proven for preparation of three general types of radioactive xenon standards: pure isotopes for photon energy quality control check standards, quantitative blends of pure isotopes for isotope ratio quality control check standards, and quantitative blends of various isotopes quantitatively blended with air for determination of radioactive xenon isotopes collected from air.

The individual quality control check standards, with a volume on the order of 5 SCM, were aliquots from a large batch that had been tested for uniformity. These standards have been subsequently analyzed in good agreement with the expected values. The certified values are based on the activity and mass. This method of large-scale sample preparation has proven to be a valid technique for testing multiple stations located in different parts of the world on the same basis. The test sample preparation methods presented here are designed to be applied to single sets of equipment and equipment at multiple locations (i.e., as with the International Monitoring System).

These standards are needed to ensure that all operating Comprehensive Test-Ban-Treaty facilities are operating on the same basis; therefore, when a suspicious seismic event coincides with radioactive xenon detection, the xenon ratios have sufficient validity to be used to back calculate the time of production of the xenon species. This verification must have a high level of accuracy to ensure that the xenon really is from a detonation and not from a local leaking fuel rod or from medical isotope production.

\section{Acknowledgements}

This work is supported by the U.S. Department of Energy, under DOE Idaho Operations Office Contract DE-AC07-05ID14517. Accordingly, the U.S. Government retains a non-exclusive, 44 royalty-free license to publish or reproduce the published form of this contribution, or allow 45 others to do so, for U.S. Government purposes. 
This information was prepared as an account of work sponsored by an agency of the U.S. Government. Neither the U.S. Government nor any agency thereof, nor any of their employees, makes any warranty, express or implied, or assumes any legal liability or responsibility for the accuracy, completeness, or usefulness of any information, apparatus, product, or process disclosed, or represents that its use would not infringe privately owned rights. References herein to any specific commercial product, process, or service by trade name, trademark, manufacturer, or otherwise, does not necessarily constitute or imply its endorsement, recommendation, or favoring by the U.S. Government or any agency thereof. The views and opinions of authors expressed herein do not necessarily state or reflect those of the U.S. Government or any agency thereof.

\section{References}

Appelhans, A. D., Delmore, J. E., Olson, J. E., 2005. Wide dispersion multiple collector isotope ratio mass spectrometer. Int. J. of Mass Spectrom. 241, 1-9.

Auer, M., Axelsson, A., Blanchard, X., Bowyer, T. W., Brachet, G., Bulowski, I., Dubasov, Y., Elmgren, K., Fontaine, J. P., Harms, W., Hayes, J. C., Heimbigner, T. R., McIntyre, J. I., Panisko, M. E., Popov, Y., Ringbom, A., Sartorius, H., Schmid, S., Schulze, J., Schlosser, C., Taffary, T., Weisse, W., Wernsperger, B., 2004. Intercomparison experiments of systems for the measurement of xenon radionuclides in the atmosphere. Appl. Radiat. and Isot. 60, 863-877.

Auer, M., Kumberg, T., Sartorius, H., Wernsperger, B., Schlosser, C., 2010. Ten Years of Development of Equipment for Measurement of Atmospheric Radioactive Xenon for the Verification of the CTBT. Pure and Appl. Geophys. 167, 471-486.

Auer, M., Prior, M. K., 2014. A new era of nuclear test verification. Phys. Today 67, 39-44.

Bowyer, T. W., Hayes, J. C., Reeder, P. L., Panisko, M. E., Pitts, W. K., McIntyre, J. I., Abel, K. H., Thompson, R. C., Heimbigner, T. R., Warner, R. A., 2000. Automated Radioxenon Sampler-Analyzer: Detection of radioactive xenon for the CTBT. Abstr. of Papers of the Am. Chem. Soc. 220, U17-U17.

Bowyer, T. W., Schlosser, C., Abel, K. H., Auer, M., Hayes, J. C., Heimbigner, T. R., McIntyre, J. I., Panisko, M. E., Reeder, P. L., Satorius, H., Schulze, J., Weiss, W., 2002. Detection and analysis of xenon isotopes for the comprehensive nuclear-test-ban treaty international monitoring system. J. of Environ. Radioact. 59, 139-151.

Dubasov, Y. V., Popov, Y. S., Prelovskii, V. V., Donets, A. Y., Kazarinov, N. M., Mishurinskii, V. V., Popov, V. Y., Rykov, Y. M., Skirda, N. V., 2005. The APIKC-01 automatic facility for measuring concentrations of radioactive xenon isotopes in the atmosphere. Instrum. and Exp. Tech. 48, 373-379.

Fontaine, J. P., Pointurier, F., Blanchard, X., Taffary, T., 2004. Atmospheric xenon radioactive isotope monitoring. J. of Environ. Radioact. 72, 129-135.

Haas, D. A., Biegalski, S. R., Biegalski, K. M. F., 2009. Radioxenon production through neutron irradiation of stable xenon gas. J. of Radioanal. and Nuc. Chem. 282, 677-680.

McGrath, C. A., Houghton, T. P., Pfeiffer, J. K., Hague, R. K., 2013. Xe-135 production from Cf-252. J. of Radioanal. and Nuc. Chem. 296, 893-897.

Perajarvi, K., Eronen, T., Elomaa, V. V., Hakala, J., Jokinen, A., Kettunen, H., Kolhinen, V. S., Laitinen, M., Moore, I. D., Penttila, H., Rissanen, J., Saastamoinen, A., Toivonen, H., Turunen, J., Aysto, J., 2010. Ultra-high resolution mass separator-Application to detection of nuclear weapons tests. Appl. Radiat. and Iso. 68, 450-453. 
1 Ringbom, A., Larson, T., Axelsson, A., Elmgren, K., Johansson, C., 2003. SAUNA - a system for automatic sampling, processing, and analysis of radioactive xenon. Nuclear Instrum. \& Methods in Phys. Res. Sect. A-Accel. Spectrom. Detect. and Assoc. Equip. 508, 542553.

Ringbom, A., Axelsson, A., Aldener, M., Auer, M., Bowyer, T. W., Fritioff, T., Hoffman, I., Khrustalev, K., Nikkinen, M., Popov, V., Popov, Y., Ungar, K., Wotawa, G., 2013. Radioxenon detections in the CTBT international monitoring system likely related to the announced nuclear test in North Korea on February 12, 2013. J. of Environ. Radioact. 128, 47-63. 

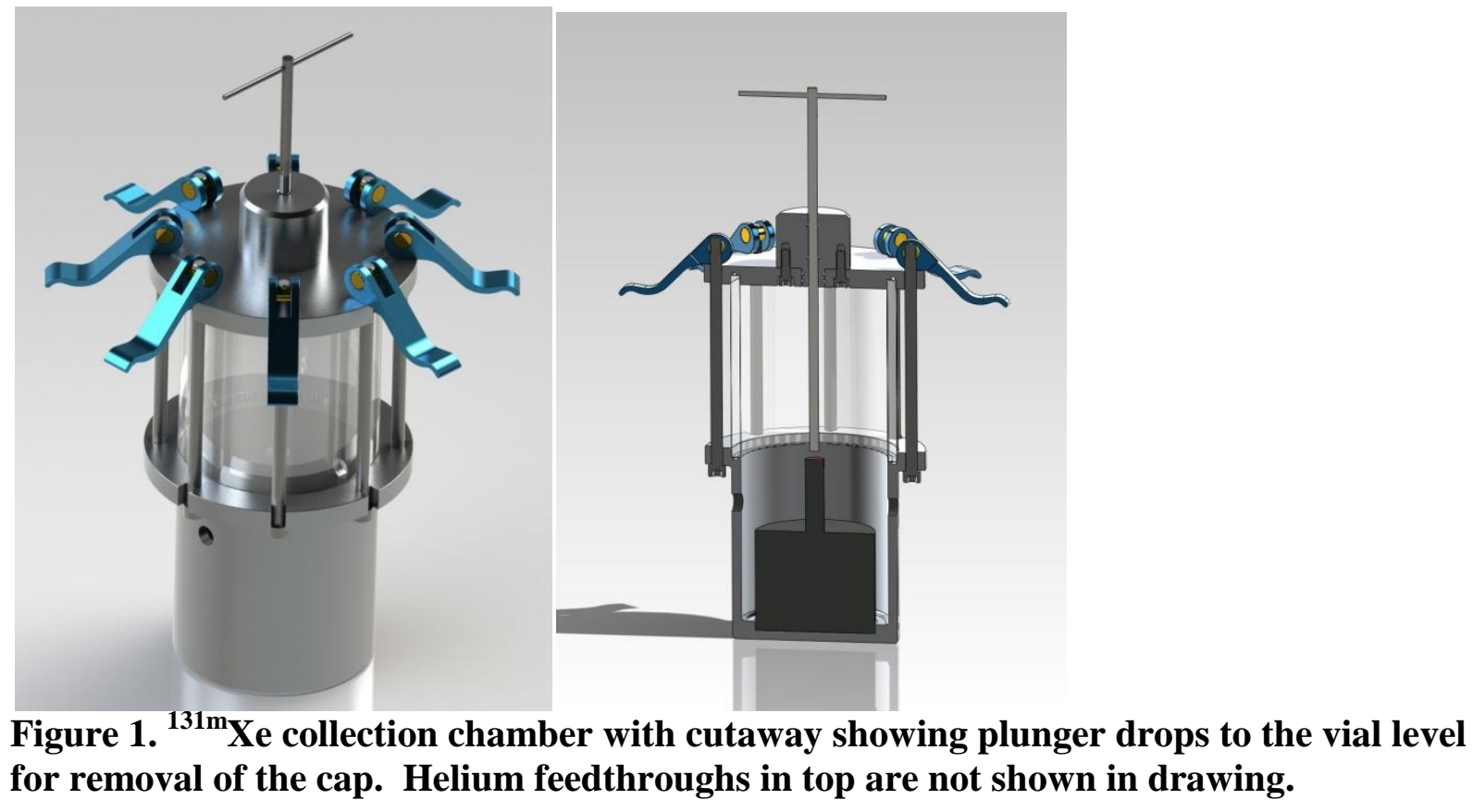

Figure $1 .{ }^{131 \mathrm{~m}}$ Xe collection chamber with cutaway showing plunger drops to the vial level
for removal of the cap. Helium feedthroughs in top are not shown in drawing.

Figure $1 .{ }^{131 \mathrm{~m}}$ Xe collection chamber with cutaway showing plunger drops to the
for removal of the cap. Helium feedthroughs in top are not shown in drawing.

.




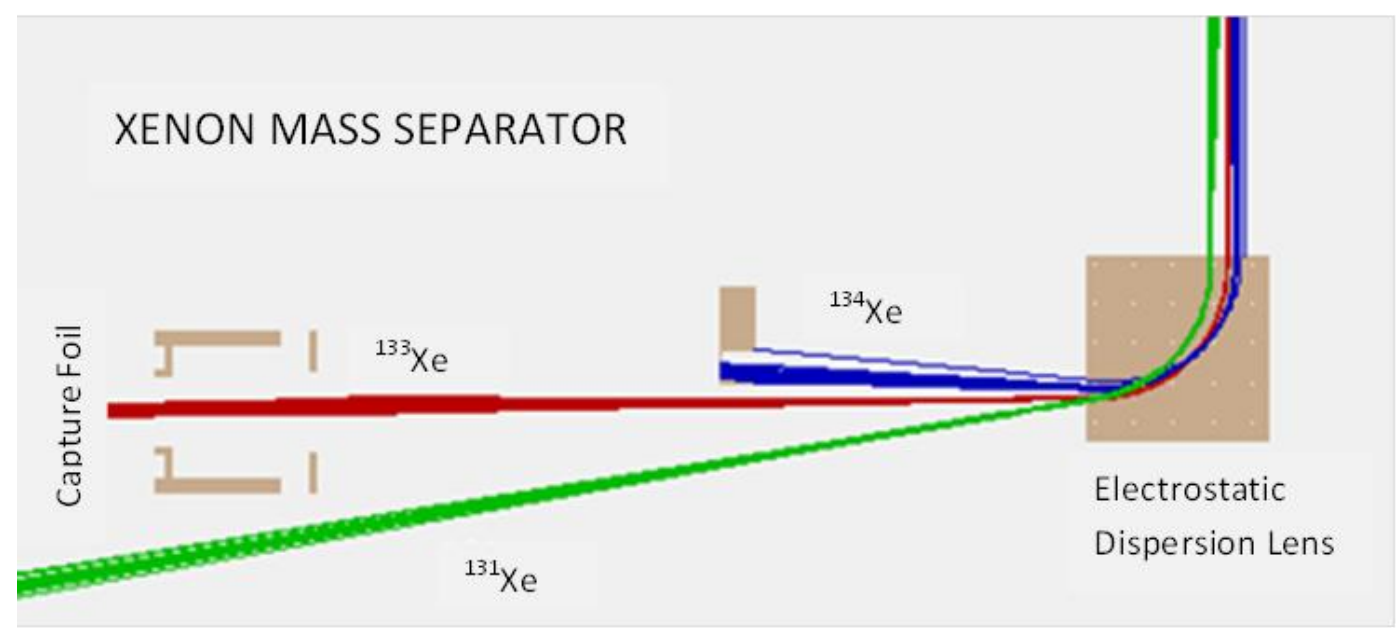

Figure 2. Ion optic model drawing of the xenon mass separator. The wide separation between ${ }^{133} \mathrm{Xe}$ and ${ }^{131 \mathrm{~m}} \mathrm{Xe}$ is shown, along with ${ }^{134} \mathrm{Xe}$ used to monitor on a faraday cup. The ${ }^{133} \mathrm{Xe}$ is implanted in an aluminum foil. 


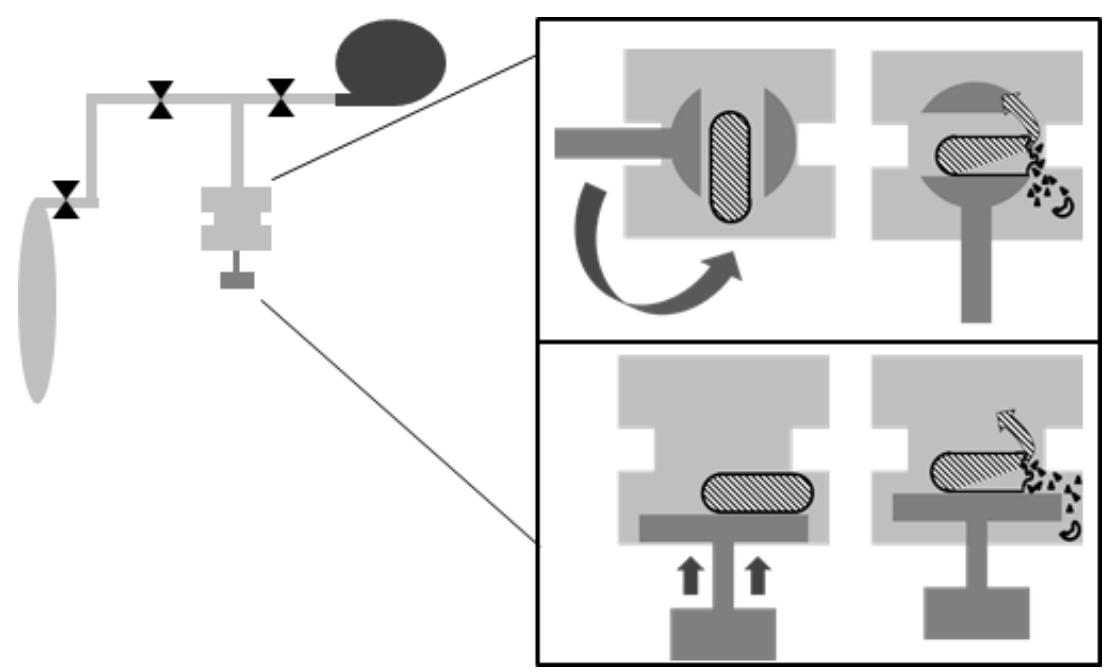

Figure 3. Manifold with destination vessel for cryogenic transfer, vacuum, and bean crushing valve. The enlargement image shows two different versions of valves used to crush beans. A ball valve and a vacuum plunger valve. 


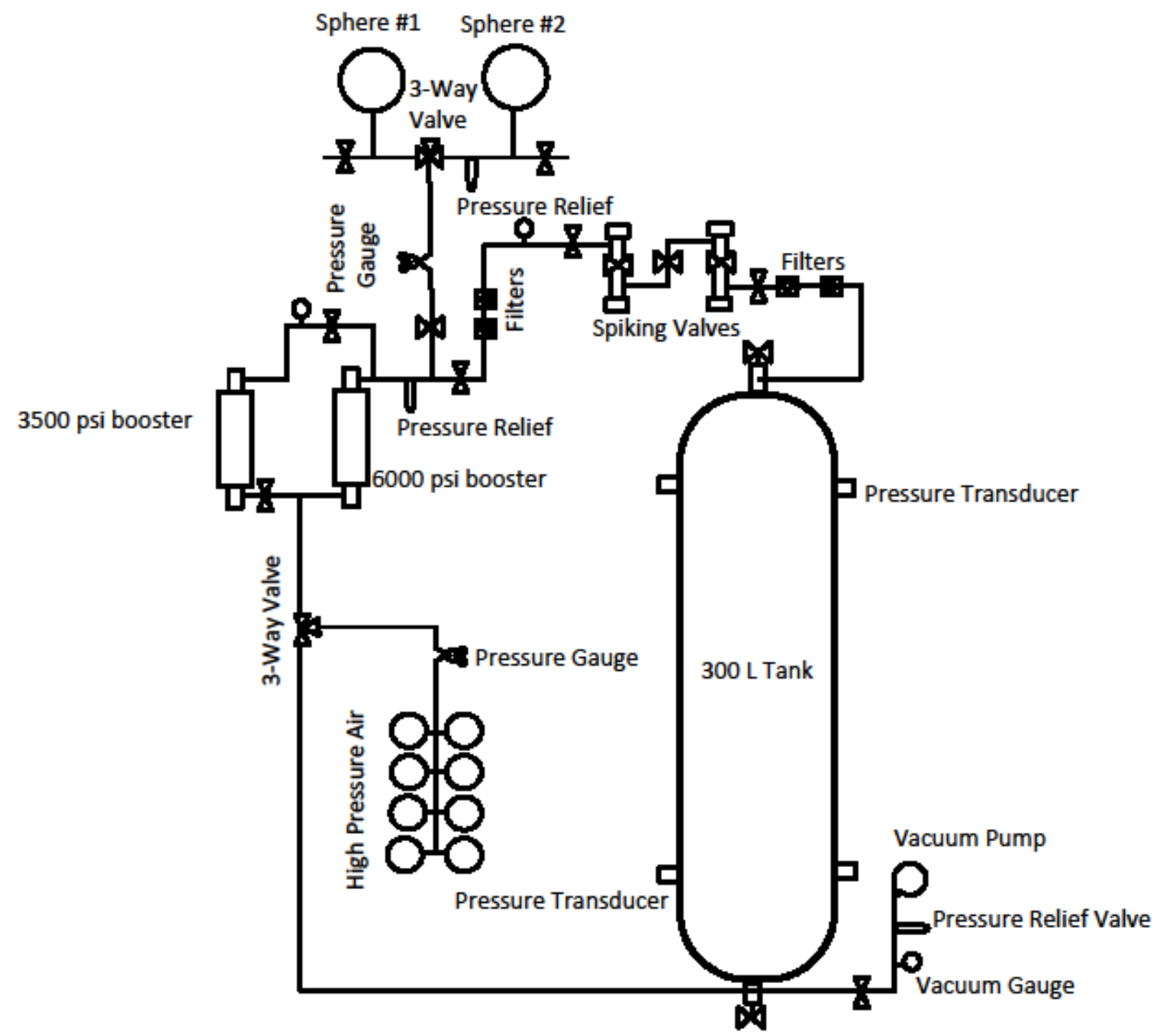

Figure 4. 300-L cylinder diagram showing the source air for filling, booster pumps for recycling and filling spheres, and spike breaking valves to introduce radioactive xenon to the recycle loop. 
Table 1. Sample 1, 5.18 SCM of air.

\begin{tabular}{|c|c|c|}
\hline$\frac{\text { Isotope }}{{ }^{133} \mathrm{Xe}}$ & $\frac{\text { DPM }}{260 \pm 50}$ & $\frac{\text { DPM/SCM }}{630 \pm 10}$ \\
${ }^{133 \mathrm{~m}} \mathrm{Xe}$ & $133 \pm 40$ & $25.7 \pm 7.7$ \\
${ }^{135} \mathrm{Xe}$ & $\mathrm{ND}$ & $\mathrm{ND}$ \\
\hline
\end{tabular}


Table 2. Sample 2, 4.96 SCM of air.

\begin{tabular}{|c|c|c|}
\hline$\frac{\text { Isotope }}{{ }^{133} \mathrm{Xe}}$ & $\underline{\text { DPM }}$ & $\frac{\text { DPM/SCM }}{627 \pm 10}$ \\
${ }^{133 \mathrm{~m}} \mathrm{Xe}$ & $172 \pm 26$ & $34.6 \pm 5.2$ \\
${ }^{135} \mathrm{Xe}$ & $12,700 \pm 2,000$ & $2,180 \pm 180$ \\
\hline
\end{tabular}


Table 3. Sample 3, 4.93 SCM of air.

\begin{tabular}{|c|c|c|}
\hline Isotope & $\underline{\text { DPM }}$ & $\frac{\text { DPM/SCM }}{625 \pm 10}$ \\
${ }^{133} \mathrm{Xe}$ & $3,082 \pm 49$ & $50.5 \pm 10.5$ \\
${ }^{133 \mathrm{me}}$ & $249 \pm 52$ & $\mathrm{ND}$ \\
${ }^{135} \mathrm{Xe}$ & $\mathrm{ND}$ & \\
\hline
\end{tabular}


Table 4. Sample 4, 4.89 SCM of air.

\begin{tabular}{|c|c|c|}
\hline Isotope & $\underline{\text { DPM }}$ & DPM/SCM \\
${ }^{133} \mathrm{Xe}$ & $3,047 \pm 50$ & $623 \pm 10$ \\
${ }^{133 \mathrm{~m}} \mathrm{Xe}$ & $76.2 \pm 10.5$ & $15.6 \pm 2.1$ \\
${ }^{135} \mathrm{Xe}$ & $10,000 \pm 1,200$ & $2,070 \pm 190$ \\
\hline
\end{tabular}

